\title{
Five Factor Model of Personality and the Use of Multiple Internet Functions
}

\author{
John Magnus Roos ${ }^{1,2}$ \\ ${ }^{1}$ School of Health and Education, University of Skövde, Skövde, Sweden \\ ${ }^{2}$ Centre for Consumer Science, University of Gothenburg, Gothenburg, Sweden \\ Email: magnus.roos@his.se
}

How to cite this paper: Roos, J.M. (2017) Five Factor Model of Personality and the Use of Multiple Internet Functions. Open Journal of Social Sciences, 5, 109-116. https://doi.org/10.4236/jss.2017.510010

Received: July 26, 2017

Accepted: October 10, 2017

Published: October 13, 2017

\begin{abstract}
The purpose of this study is to explore how the Five Factor Model of Personality relates to the use of multiple internet functions. The personality traits included in the Five Factor Model of Personality are Openness to Experiences, Conscientiousness, Extraversion, Agreeableness and Neuroticism. This study builds on survey data from a sample that is representative of the Swedish population. In total, 3400 surveys were distributed with a response rate of 50 percentages $(N=1694)$. Our results indicate that use of multiple internet functions are positively related to Openness to Experiences and Extraversion, and negatively related to Neuroticism.
\end{abstract}

\section{Keywords}

Personality, Five Factor Model of Personality, Internet Use, Multiple Internet Functions

\section{Introduction}

Previous research has indicated that personality traits are strongly related to internet use and a main factor to study in order to understand different users' online behavior [1] [2].

The majority of the studies on personality and internet use have involved only one internet function (e.g. social media, shopping). According to Kim and Jeong (2015), researchers are aware that a variety of individual differences exists among internet users. However, researchers in the field of personality and internet usage have not focused on the variety among users when it comes to using multiple functions [1].

"Use of multiple internet functions" relates to the number of internet activities a person use [2]. Internet provides more and more functions that user can be 
engaged in, ranging from simple emails and information-search, to social networks, blogs and online games. One user might for instance be engaged in online-shopping but not in social media, while another user might use both online-shopping and social media. The overall research question is "What personality traits determine the number of internet functions a person use?"

\section{The Five Factor Model of Personality}

The Five Factor Model of Personality, the most frequently used typology of personality, positing that there are five major and universal dimensions of personality; Openness to Experience, Conscientiousness, Extraversion, Agreeableness and Neuroticism [3]. Openness to Experience is associated with behavioral flexibility, intellectual curiosity, aesthetic sensitivity, vivid imagination and unconventional attitudes. People high on Openness to Experience are intellectually curious, willing to try new things and more creative and imaginative, while people low on Openness to Experience is more cautious and conservative. Conscientiousness is associated with planning, responsibility, self-discipline, order and dutifulness. People high on Conscientiousness are thorough and efficient, while people low on Conscientiousness are spontaneous, careless and irresponsible. It is related to the way people control and regulate their emotions. Extraversion is associated with social behavior and extrinsic motivation. People high on Extraversion are more outgoing and sensitive for external stimuli, while people low on Extraversion are reserved and withdrawn and primary intrinsically motivated. Agreeableness is associated with friendliness, trust, tender-mindedness and altruism. People high on Agreeableness are trusting and forgiving, sometimes a bit naïve. People low on Agreeableness is hostile, suspicious and competitive. Neuroticism is associated with anxiety, vulnerability, worrying and low self-confidence. People high on Neuroticism are anxious and nervous, while people low on Neuroticism (i.e. Emotionally Stable) are calm and relaxed [3] [4].

\section{Literature Review and Hypotheses Development}

\subsection{Literature Review}

To the best of our knowledge, there is only one study [2] on the Five Factor Model of Personality and the use of multiple internet functions. The previous study used data from a large-scale survey of 9479 Korean media users. According to Kim and Jeong (2015) Openness to Experience is positively associated with using more internet functions $(\beta=0.029, p<0.0001)$. Individuals who scored higher on Conscientiousness are also more likely to use a number of internet functions $(\beta=0.014, p<0.0001)$. Further, Neuroticism is positively associated with using more internet functions $(\beta=0.020, p<0.0001)$. In contrast to the three personality traits that significantly relate to using multiple internet functions, Extraversion and Agreeableness were unrelated to use of multiple internet functions [2]. 


\subsection{Hypotheses Development}

Based on the previous study [2], the following hypotheses were developed:

Hypothesis 1. Openness to Experiences should be positively related to use of multiple internet functions.

Hypothesis 2. Conscientiousness should be positively related to use of multiple internet functions.

Hypothesis 3.Neuroticism should be positively related to use of multiple internet functions.

\section{Research Design}

\subsection{Sample and Procedure}

The data were used from a panel (omnibus) study, the National SOM-survey. The SOM-institute belongs to the University of Gothenburg and collects data on individuals on a wide variety of measures such as political opinion, media use, consumption, employment, education, health, and social well-being. The $\mathrm{Na}$ tional SOM-survey uses a systematic probability sample of 3400 Swedish residents in the age $16-85$.

A postal questionnaire was randomly sent out to 3400 people, which recipients were invited to complete and return anonymously. Tre response rate was 53 percent. Given attrition and missing values, the actual sample size of our study was 1694 (50 percentage of the sample). The data was gathered between September 2014 and February 2015 [5].

\subsection{Participants}

One thousand six hundred and ninety-four respondents (762 men, 932 women) were answering a questionnaire. Ages ranged from 16 to 85 with a mean of 52.3 years. The sample demography is representative for the Swedish population [5].

Regarding internet use, 9.9 percent $(n=168)$ of the respondents did not use internet anytime during the last 12 months, 2.5 percent used internet less than one time per week, 5 percent used internet on a weekly basis, 11.7 percent used internet several times every week, 71 percent $(n=1203)$ use internet for at least one function every day.

\subsection{Variables and Measurements}

\subsubsection{Personality}

The measure of personality, BFI-10, is a 10-item measure of The Big Five Inventory, with 2 items of each of the Big Five traits of Openness to Experiences, Conscientiousness, Extraversion, Agreeableness and Neuroticism. The BFI-10 has adequate levels of test-retest reliability and convergent and discriminant validity [6].

Variables for the personality traits consisted of the mean scores based on the two items set on a five-point Likert scale, ranging from 1 ("strongly disagree") to 5 ("strongly agree") with a midpoint of 3 ("neither agree nor disagree"). Reverse 
items have been converted before calculation. Only respondents that have indicated both items have received a mean score for that specific factor and thereby included in the analyses.

Openness to Experiences is constructed by the average of two items; "has few artistic interests" and "has an active imagination" ( $r=0.16, p<0.01, M=3.04)$. Conscientiousness is constructed by the average of; "tend to be lazy" (reversed) and "does a thorough job" $(r=0.21, p<0.01, M=4.00)$. Extraversion is constructing by the average of; "is reserved" (reversed) and "is outgoing, sociable" ( $r$ $=0.46, p<0.01, M=3.58)$. Agreeableness is constructed by the average of; "tend to find fault with others" (reversed) and "is generally trusting" ( $r=0.04, p=0.1$, $M=3.69$ ). Neuroticism is constructed by the average of; "is relaxed, handles stress well" (reversed) and "gets nervous easily" ( $r=0.40, p<0.01, M=2.57)$.

\subsubsection{Multiple Internet Functions}

Use of multiple functions has been measured through ten internet functions (Table 1). The question asked to users was "Have you during the last 12 months used internet for $[\cdots]$ ?? for each internet function. Each function consists of a dummy variable $(1=$ yes, $0=$ no). Table 1 contains descriptive statistics for each internet function. Each function was then summed to a total of functions, ranging from 0 - 10 functions $(N=1593, M=6.58, S D=3.03)$.

\subsubsection{Gender and Age}

Prior research has found that gender and age influence internet use; men use internet more than women and younger people use internet more than older [7]. Personality theorists have also found that age and gender influence the Five Factor Model of Personality [8]. Therefore, gender and age might be confounding variables that explain a potential correlation between personality traits and use of multiple internet functions. There are also some studies that indicate that gender moderate the effect between personality factors and internet use (e.g. [9]

Table 1. Popularity of use of internet fuctions per year for the Swedish population $(N=$ 1593).

\begin{tabular}{cc}
\hline Internet function & Percentage of users \\
\hline Information search & $88.7 \%$ \\
Sending emails & $85.9 \%$ \\
Banking & $80.5 \%$ \\
News & $79.1 \%$ \\
Shopping & $69.8 \%$ \\
Administrative authority & $64,8 \%$ \\
Social media & $58.9 \%$ \\
Film and TV-series & $58.7 \%$ \\
Blog reading & $50.8 \%$ \\
Online gaming & $22.4 \%$ \\
\hline
\end{tabular}


[10]). In the present study, we will control for the effects from gender $(1=\mathrm{fe}-$ male, $0=$ male) and age (actual age) on use of multiple internet functions.

\subsection{Statistical Analyzes}

To examine the association of the Five Factor Model of Personality and using multiple internet functions, we used a hierarchical multiple regression analyses. Multiple internet functions are the dependent variable. Age and gender are independent variables included in the first block, followed by a second block involving the five personality traits. All statistical analyzes were performed with IBM SPSS Statistics 24.

\section{Results}

The percentages of how the Swedish population uses different types of internet functions are presented in Table 1. During the last 12 months, 88.7 percent of the Swedish populations had used internet to search for information. This is the most popular internet function, followed by using e-mails ( 85.9 percent). The number of internet functions used indicates that the largest proportion of internet users tended to have used nine of the ten functions (21.7 percent), followed those who had used eight (15.2 percent), ten (12.7 percent), seven (12.4 percent), zero (10.4 percent), six (9.8 percent), five (7.6 percent), four (4.1 percent), three (3.4 percent), two (1.9 percent), and one ( 0.9 percent) functions.

To examine the influence on the Five Factor Model of Personality factors on using multiple Internet functions, we conducted a hierarchical regression analysis. Model 1 predicts using multiple internet functions with aged and gender, whereas Model 2 adds the Five Factor Model of Personality as the second block. The findings are presented in Table 2.

Table 2 shows that, after controlling for age and gender, personality factors significanlty $(p<0.001)$ can explain the variance in using multiple internet fun-

Table 2. Hierarchical regression model exploring how age, gender and personality predict multiple internet use $(N=1468)$.

\begin{tabular}{ccc}
\hline Independent variables & Block 1: Age, Gender B & Block 2: Personality B \\
\hline Age & $-605^{\star *}$ & -0.595 \\
Gender & $-0.045^{*}$ & $-0.51^{\star * *}$ \\
Big Five personality factors & \\
Openness to Experiences & & $0.077^{\star * *}$ \\
Conscientiousness & -0.031 \\
Extraversion & & $0.076^{* * *}$ \\
Agreeableness & & -0.033 \\
Neuroticism & 0.363 & $-0.56^{*}$ \\
Adjusted $\mathrm{R}^{2}$ & & 0.377 \\
\hline
\end{tabular}

Note. $\mathrm{B}=$ Beta, the standardized regression coefficient. ${ }^{*} p<0.05 ;{ }^{* *} p<0.01 ;{ }^{* *} p<0.001$. 
citions. Openness to Experiences, Extraversion and reverse Neuroticism (i.e. Emotional Satbility) are positively related with using more internet funcitons. In contrast to the three personality factors that significantly relate to using multiple internet fuctions, Conscientiousness and Agreeaablness are unrelated.

\section{Discussion}

Our result shows that Openness to Experiences is positively associated to use of multiple internet functions, which provides support for Hypothesis 1. It is not surprising that the result indicated that Openness to Experiences is positively related to using multiple internet functions. People with a high degree of Openness to Experiences have in general more interests than people with a low degree of Openness to Experiences and they are more likely to be curious, aesthetic and imaginative [3], which motivate them to engage with multiple internet functions to pursue their needs and interests. This finding is also in line with the prior study on personality traits and use of multiple internet functions [2].

This study indicated a positive relationship between Extraversion and using more internet functions. This result was not found by the prior study on personality traits and use of multiple internet functions [2]. Considering the Five Factor Model of Personality, this finding is not very surprising. Extraverts seek stimulation from sources outside of themselves and might therefore be attracted to a range of features that the internet provides [3]. Further, extraverts like to socialize and the internet is offering a variety of social activities (e.g. social media and online gaming).

This study indicates that Neuroticism is negatively related to using multiple internet functions. Stated differently, a person with a high degree of Emotional stability is likely to use more internet functions than a person with a low degree of Emotional stability. This finding is in opposite direction to what we asserted for Hypothesis 3 and contradicts therefore prior study [2]. The underlying logic by Kim and Jeong (2015) suggest that those who are high on Neuroticism use multiple internet functions in order to feel a sense of "belonging" and thereby reduce their loneliness, anxiousness and shyness [2]. Our study indicates the opposite, that Swedish people that use a lot of activities primarily are emotionally stable.

\section{Conclusions}

In line with hypothesis 1, our results show that Openness to Experiences is positively related to use of multiple internet functions. In the present study, Conscientiousness was unrelated to the use of multiple internet functions, which differ from prior study and hypothesis 2. Our results show that Extraversion is positively related to use of multiple internet functions. Again, our results differ from the national-wide study in Korea, showing that Extraversion is unrelated to multiple internet functions [2]. As expected, degree of Agreeableness was unrelated to use of multiple internet functions. Contradicting our hypothesis 3, our 
results show that Neuroticism is negatively related to use of multiple internet functions. To summarize, the two national-wide studies on the Five Factor Model of Personality and use of multiple internet functions differ on three of five traits.

One explanation to the different findings might be cultural differences. Another explanation might be related to different years of data collection. The conflicting findings reported in this paper might reflect how internet evolves over time. The data for the Korean national-wide study was collected in 2012, while the data for the present study was collected in 2014 and 2015. The two studies also differed in several methodological aspects (e.g. population frame, inclusion criteria, internet functions, personality inventory). However, when it comes to Neuroticism we do not think that the different findings completely can be explained through methodological issues. Both studied controlled for gender and age and both studies used a 10-items personality inventory. We suggest further research in order to understand the relationship between the use of multiple internet functions and personality traits, especially related to Neuroticism.

\section{Acknowledgements}

The funding source was designated research time at University of Skövde, Sweden. Acknowledgment to the SOM-Institute, University of Gothenburg, for the data.

\section{References}

[1] Amichai-Hamburger, Y. (2007) Pesonality, Individual Differences and Internet Use. In: Johnson, A., McKenna, K., Postmes, T. and Reips, U., Eds., The Oxford Handbook of Internet Psychology, Oxford University Press, Oxford, 187-204.

[2] Kim, Y. and Jeong, J.S. (2015) Personality Predictors for the Use of Multiple Internet Functions. Internet Research, 25, 399-415. https://doi.org/10.1108/IntR-11-2013-0250

[3] Costa, P.T. and McCrae, R.R. (1995) Domains and Facets: Hierarchical Personality Assessment Using the Revised NEO Personality Inventory. Journal of Personality Assessment, 64, 21-50. https://doi.org/10.1207/s15327752jpa6401 2

[4] Digman, J.M. (1990) Personality Structure: Emergence of the Five-Factor Model. Annual Review of Psychology, 41, 417-440. https://doi.org/10.1146/annurev.ps.41.020190.002221

[5] Vernersdotter, F. (2015) Den nationella SOM-undersökningen. In: Bergström, A., Johansson, B., Oscarsson, H. and Oskarson, M., Eds., Fragment, University of Gothenburg: The SOM-Institute, 563-588.

[6] Rammstedt, B. and John, O.P. (2007) Measuring Personality in One Minute or Less: A 10-Items Short Version of the Big Five Inventory in English and German. Journal of Research in Personality, 41, 203-212. https://doi.org/10.1016/j.jrp.2006.02.001

[7] Hills, P. and Argyle, M. (2003) Uses of the Internet and Their Relatioships with Individual Differences in Personality. Computers in Human Behavior, 19, 59-70. https://doi.org/10.1016/S0747-5632(02)00016-X

[8] Soto, C.J., John, O.P., Gosling, S.D. and Potter, J. (2011) Age Differences in Personality Traits from 10 to 65: Big Five Domains and Facets in a Large Cross-Sectional 
Sample. Journal of Personality and Social Psychology, 100, 330-348.

https://doi.org/10.1037/a0021717

[9] Hamburger, Y.A. and Ben-Artzi, E. (2000) The Relationship between Extraversion and Neuroticism and the Different Uses of the Internet. Computers in Human Behavior, 16, 441-449. https://doi.org/10.1016/S0747-5632(00)00017-0

[10] Correa, T., Hinsley, A.W. and de Zúñiga, G. (2010) Who Interacts on the Web?: The Intersection of Users' Personality and Social Media Use. Computers in Human Behavior, 26, 247-253. https://doi.org/10.1016/j.chb.2009.09.003 